\title{
The Problem of Experience in the Study of Organizations
}

\author{
Lloyd E. Sandelands, V. Srivatsan*
}

Lloyd E.

Sandelands

Departments of

Organizational

Behaviour and

Psychology,

University of

Michigan,

Ann Arbor,

U.S.A.

V. Srivalsan

Department of

Organization

Studies. Columbia

University. New

York, U.S.A.
Organization

Studies

1993, 14/1:

001-22

(C) $1993 \mathrm{EGOS}$

0170-8406/93

$0014-0001 \$ 2.011$

\section{Abstract}

This paper deals with the fact that we cannot experience large organizations directly, in the same way as we can experience individuals or small groups, and that this non-experientiability has certain implications for our scientific theories of organizations. Whereas a science is animated by a constructive interplay of theory concepts and experience concepts, the study of organizations has been confined to theory concepts alone. Implications of this analysis for developing a science of organizations are considered.

\section{Introduction}

In science, as everywhere else, seeing is believing. According to James (1911), science consists in the substitution of a conceptual order for the perceptual order of experience. Russell (1921) insisted that scientific theory should be founded upon perceptual experience of some kind. In his terms, 'knowledge by description' presupposes 'knowledge by acquaintance'. To put this principle most colourfully, Wheelwright (1962) described the aim of theory as being to 'chop at the joints' - that is, to mark off resemblances and differences where experience says it is most natural to do so.

For the field of organization studies, this principle is an embarrassment. Organizations cannot be perceived, and therefore cannot be unambiguously theorized. To the question: 'What is organization theory about?' there is no easy or ready reply. The research literature offers a dismaying multiplicity of possibilities, not one of which is recognizably definitive. To some authors organization theory is about bureaucracy, to others it is about systems of information and/or energy. to others it is about populations of social forms, to still others it is about modes of exchange (c.g. markets, hierarchies, and clans), and to still others, it is about patterns of meaning or culture. These stopgaps are questionable in the same measure; for about systems, markets, hierarchies, clans and cultures, there is an equal ration of indefiniteness. Disagreement is possible because perceptive experience offers little to agree about.

In this article. we show how the absence of perceptive experience of organizations makes it difficult to theorize about them scientifically. In 
fundamental respects, ours is an exposition and application of contemporary ethnomethodological critiques of social science (e.g. Garfinkel 1967; 1988: Hilbert 1990) to the field of organization studies. Parallelling those critiques, we argue that scientific conceptualization of organizations must be premised on phenomenological insights. Whereas science comes to life in the dynamic opposition of phenomenal experience and explanation; in the absence of this opposition, it dissipates to a desultory exercise of hopes. The fact that the 'organization' conforms to no definite experience (i.e., that it cannot be perceived, nor even imagined) means that the study of organizations is deprived of this life-giving dynamic. Perhaps the clearest sign of this is the strange inversion of discourse that occurs in organization studies where, amidst the lively discussion of concepts and theories, there is barely a whisper about how organizations should be conceived or operationalized. Finally, we discuss the prospects for a science of organizations and what might be done to improve them.

\section{Organizations in Doubt}

We find it natural to speak of organizations as objects in action. Indeed, our language is built upon a grammar of object and predicate (to the chagrin of advocates of a more fluid language of process, e.g. . Whitehead 1933; Giddens 1979). Even though grammatical form is not the same thing as phenomenal form, we are likely to mistake the two when there is no concrete experience to keep them separate. As Wittgenstein (1953: 42-49) pointed out, our problems of thought are primarily grammatical. A 'main source of our failure to understand', he wrote, 'is that we do not command a clear view of the use of our words'.

\section{Uncertain Substance}

The problems of studying organizations begin with the difficulty of pointing them out - to gesture and say. 'This is an organization.' This contrasts with the natural sciences where gesturing and saying are often easier and more convincing. Pointing makes definition easy because it frees us from having to translate what we can see into words. However, in the case of organizations, there is nothing obvious to point to, or to exclaim about. The word 'organization' names something that cannot be seen, and thus that cannot otherwise be confirmed as an object.

To be sure, the research literature on organizations offers almost no hint that this is, or could be, a problem. Although it is sometimes acknowledged that the boundaries of organizations are problematic (e.g., Katz and Kahn 1978; Weick 1979), there is little question that organizations are genuine objects. The overwhelming majority of empirical studies report no difficulties of identification or measurement. For example, in the last 5 years (1986-1990) of the Administrative Science Quarterly, a 
well-known and respected journal of empirical research on organizations, we counted 85 studies which referred to over 204,000 organizations or units thereof, ranging from Fortune 500 corporations to Finnish newspapers to small convenience stores to school districts and classes. Not one of these voices a serious misgiving about the existence of the organization(s) under study. Only two of these studies suggest that the idea of organization could be empirically problematic. Barnett and Carroll (1987) analyze the structure of competition and mutualism among early phone companies in Southeast Iowa and find that the dynamics of selection are based on communities of organizations, not individual organizations. Fiol (1989) notes that in letters to corporate shareholders, chemical companies that are engaged in joint ventures with other companies speak about their identity in more uncertain terms, and have a less well-defined sense of their external boundaries (although their sense of internal boundaries may be enhanced). However, even in these cases, there is no suggestion that the concept of organization should be abandoned, or indeed that it does not refer to an actual entity. The 'fact' of organization is sure enough for research to proceed.

This raises the question of how researchers 'know' organizations when they cannot see them, and when they cannot deduce them from things that they can see. In most instances, organizations are identified by their legal standing (e.g., articles of association or incorporation filed with local, state, or national governments, charters, filings with Security and Exchange Commissions, or named parties to contracts). Indeed, in the typical research study, a sample of organizations is chosen from a list of such entities (e.g., the Fortune 500, trade publications, government records). In other instances, organizations such as strategic business units, departments, or manufacturing plants, are defined by their formal place or position within larger organizational systems. This legal or positional abstraction then serves as a point of reference which can be used to locate and coordinate elements of the organization (e.g.. employees, assets, physical plant, roles, rules) which, unlike the abstraction, can be observed and quantified. These elements are united by the assumption that they refer to the same abstraction.

This manoeuver establishes the idea of an organization within a conceptual framework of law or a formal structure, and it establishes the elementary contents of the organization, but it does not establish the organization itself as an object or substance. When we look for organizations, all we see are its presumed pieces (e.g. . a leader, co-workers, a building or two, actions taken, suppliers, clients, products, a logo or advertising jingle, a retirement plan). Instead of an image of the organization, we have images of disparate objects and events that are supposed to constitute an unseen whole. Such an enumeration of perceptible parts no more defines an organization than a parts-list defines an automobile. 


\section{Reification}

Our belief in organizations is sustained by our natural tendency to reify. Reification occurs when an arrangement of parts (a relation) is taken to be an integral whole (an object). Unlike objects such as 'dog' and 'beer can", which can be perceived and described qualitatively (e.g. by their colour, weight, shape, etc.) and which can be illustrated by instances or representations (e.g. drawings, figures, photographs), the 'organization' cannot be perceived or described qualitatively, and can be illustrated only by its constituent parts and relations. This is reflected in the ways organization is defined (see Table 1 for examples). Sometimes the organization is defined as an arrangement or system, typically of persons, activities, or roles (e.g. Barnard 1938; Katz and Kahn 1978; Simon 1976; Weick 1979). Sometimes it is defined by its functions or purposes (e.g. Selznick 1957; Scott 1981), and sometimes as something that we just know (e.g. Blau and Scott, 1962; March and Simon. 1958). In the dictionary, organization is defined as: 'A number of persons or groups having specific responsibilities and united for a particular purpose' (American Heritage Dictionary, 2nd ed., 1985). Certainly, organizations are not objects in the same sense as dogs and beer cans.

Table 1

Concepts of Organization 'a system of consciously coordinated activities or forces of two or more persons' (Barnard 1938: 73).

'structures of mutual expectation, attached to roles which define what each of its members shall expect from others and from himself (cited in Weick 1979:3).

'the complex pattern of communication and relationships in a group of human bcings' (Simon 1976: xvii).

the patterned activities of a number of individuals. Moreover, these patterned activities are complementary or interdependent with respect to some common output or outcome; they are repeated, relatively enduring, and bounded in space and time' (Katz and Kahn 1978: 20).

'a technical instrument for mobilizing human energies and directing them toward set aims'. (Sclznick 1957: 5).

'a collectivity oriented to the pursuit of relatively specific goals and exhibiting a relatively highly formalized social structure'. (Scott 1981: 21).

'when we speak of an organization it is generally quite clear what we mean and what we do not mean by this term.' (Blau and Scott 1962: 2).

'It is easier. and probably more useful. to give examples of formal organizations than to define the term." (March and Simon 1958: 1)

The organization is reified when it is treated as an entity. This ignores the wide differences between an arrangement and a thing. Whereas the one is an abstraction that specifies how other things (ideas or substances) are related to one another, the other is a substance that is positioned in time and space and that can be defined by its qualities. Failure to heed these differences shows up in age-old conundrums of organization identity. What happens to the organization when a part of it is divested, or when a part of it goes home at night? What happens when its parts are 
replaced? Is it the same organization, or a new one? More pointedly. what happens when the replaced parts are reassembled elsewhere (as happens with baseball teams on Old-timer's Days, and is beginning to happen with old rock and roll bands)? Which is the genuine organization, the one that persisted or the one that was reconstituted? Such problems of identity arise when a relation or pattern is mistaken for an entity.

\section{Phantom Actions}

Where there are doubts about organizations, there are doubts no less about their actions. Organization theory is also silent about how organizations behave and about how they are born, develop, and disintegrate (Mohr 1982: Sandelands and Drazin 1989). and this is in spite of avowals to the contrary. such as appear in descriptions of organizations as opensystems adapting to environments (e.g. Katz and Kahn 1978: Thompson 1967: Lawrence and Lorsch 1967). Helpful as the metaphor of organismic adaptation has been. it neither reflects nor points to any process that can be observed. At a close look, we find that the concept of adaptation. which shoulders the main burden of explanation, does not name a definite series of actions or events, but rather only the fact that a process exists which produces adapted organizations as its outcome (thus only repeating the fact to be explained) (see Sandelands and Drazin 1989). Adaptation may be an outcome of a process, but it is not itself a process.

The problem of specifying action takes a somewhat different form in microsociological theories of organization that focus on individual actors. There the difficulty arises in describing how individual actions (which can be specified) combine and compound to produce an organized whole. Theory begins and ends with the oft-repeated but nonetheless vague methodological principle that organization emerges from the actions of individuals (e.g. Allport 1962; Axelrod 1984; Blau 1964; Drazin and Sandelands 1992; Durkheim 1933; Homans 1967; Weick 1979). This idea, like that of adaptation, does not name a definite process, but only the notion that such a process exists. Again, what seems to be an objective process turns out not to be.

There is no harm in saying that organizations are adapted, or that they have emerged. However, problems begin when these statements are taken to signify actions or events as causes. As Ryle (1949) has pointed out, words such as adaptation and emergence have the character of achievements; they can be used to refer to processes and/or to the states produced by processes. They are deceptive when used in explanation because, by representing both the fact to be explained and the action that does the explaining, they offer a purely semantic or linguistic connection in place of what is supposed to be an empirical connection. Achievement words become necessary to provide a sense of process. and a sense of explanation, when no process is observed, and no explanation is forth- 
coming. As long as organizations are outside experience, descriptions of their actions will likewise be outside experience.

\section{Mistaken Metaphors}

Because we lack direct experiences of organizations, it has been necessary to conceptualize organizations in terms of other things which can be experienced - such as machines, biological individuals, minds, garbage cans, see-saws, or even psychic prisons. Such use of metaphors in organization studies can be read as an attempt to provide vicarious experience of an entity which cannot be experienced.

According to some authors, the virtue in having so many metaphors is that they add to understanding by calling attention to otherwise unapparent aspects of the organization (Morgan 1986). We believe to the contrary, that they are misleading and counterproductive. Instead of highlighting similarities between two experienced objects, these metaphors play upon the absence of experience by substituting for the organization an image of a metaphorical object. There is no telling whether organizations resemble organisms, machines, garbage cans, or anything else, because there no independent image or intuition of organization with which to compare them. This problem is illustrated by contrasting the organizational metaphor of organism with the astronomical metaphor of the Big Dipper. Although these metaphors appear to function the same way by giving observers tips about how to organize the facts before them, they differ fundamentally in how they relate to the facts. Whereas it is possible to point to the Big Dipper as a fact about the celestial world (to which another person could reply: 'I don't see any dipper', or 'It doesn't look a dipper to me'), it is not possible to point to an organism adapting to its environment as a fact about the organizational world (or to have the same sort of conversation about it). The latter 'fact' cannot be observed or contested in the same way.

Because organizations also differ from garbage cans, machines, organisms, and minds, it is difficult to evaluate assertions that the latter are metaphors. To wit, what does it mean to say that organizations are like machines, when machines are made of cold, lifeless parts, and organizations are made of conscious, thinking, feeling people? Certainly organizations are not machine-like in every respect, and probably only in a very few. This is no less a problem with metaphorical comparisons across types of human systems; for example, when generalizing from small groups to large, complex ones. Differences in size and complexity often betoken qualitative differences as well. Even the most obvious qualities of small groups, such as identity, order, meaning, control, or unitary culture, may be absent or undiscernible in large organizations. Indeed, it was on this basis that Van Maanen and Barley (1985) argued against the concept of corporate culture, maintaining that if such a thing existed, it is beyond the pale. They argue, both on substantive and methodological grounds, 
that it is better to focus instead on sub-groups whose cultures can be observed and studied.

Without the discipline of direct perceptive experience, we are prone to confuse organizations with the metaphors that are intended to illumine them. This confusion of map and territory can find us inhabiting a metaphorical world that is out of touch with the real world (which may be why these metaphors seem so apt; to us, they are the territory). This can be seen particularly in the conduct of research. For example, under the spell of the metaphor of organism, phenomena of organization change and development are investigated as instances of organizations adapting to environments. Inquiries are made of how organizations perceive their environments and how they adjust to them based on their perceptions. Thus. the metaphor is integral to the formulation of the research and is built into the questions that are asked. As a result, the metaphor is never questioned, much less put to test. In view of its rather blatant anthropomorphizing. there is surprisingly little doubt about whether organizations can do such things as perceive or adjust to environments.

Similar difficulties beset psychological metaphors, such as that of decision-making. Theories of microeconomics and strategic management propose that organizations, in the persons of their executive leaders (see e.g. Child 1982; Hambrick and Mason 1983), 'choose' among alternative structures or behaviours. In more sociological theories of the population ecology of organizations, this metaphor takes the form of natural selection - whereby organization environments 'decide' ('rationally', we are told) which forms of organization shall prosper or perish (see e.g. Hannan and Freeman 1977). So strong is the pull of this metaphor, that it is rarely asked whether or how such decisions are actually 'made'. Yet, in many instances, actions are taken without any consideration of alternatives. Just because alternatives to an event or course of action can be imagined does not mean that any are considered, or that a 'decision' is made between them. Although the language of 'decision-making' (and indeed of 'mind' generally) can be applied to actions. it need not be.

The crucial point, too often overlooked, is that metaphors are always misleading to one degree or another. Metaphorical comparison is dangerous when it is uncritical; when it is undisciplined by experiences with the objects or actions that are compared. Metaphor is a legitimate and indispensable tool of science when it is used to identify pattern amidst observations - that is, when it points to something that is visible but undiscerned (e.g. a pattern of stars in the case of the Big Dipper). It is an illegitimate tool of science, however, when it supplies not only the pattern but its contents as well.

\section{An Insistent Doubt}

Doubt about organizations and their actions has had a corrosive effect 
on efforts to mount a science of organizations. Allport (1962) argued that in the absence of direct perceptive experience, even seemingly unimpeachable groups such as the United States Congress, or the University, should be regarded as fictions, and not genuine scientific facts. To say that such entities declare war or play football games is but a manner of speaking (albeit often a convenient one), not a settled truth. Such talk, he argued. rests upon an error of hypostasization in which an object that cannot be denoted is treated as if it could be denoted. For example, he notes that the Congress of the United States:

... has actual denotational reference only at a step that is lower down in the natural hierarchy than the level to which it is presumed to refer. Its referent is encounterable only at the level of individuals and their actions. Ought we not, therefore, to observe the acts of the individuals and base our generalizations upon them . . . rather than attempt to describe what Congress is said to do? If we were to set ourselves to study Congress and "its" actions, would we not be starting our investigation by choosing as its object something that cannot check us to tell us whether in experiencing it we are actually experiencing something, and that cannot tell us where this "something" leaves off and some other object begins? How, with such criteria omitted at the very start, could it be claimed that the social sciences are empirical?' (p. 5).

A similar doubt about organizations has led ethnomethodologists such as Garfinkel and Hilbert to the concept of the local as the only acceptable domain for scientific investigation. Hilbert (1990) summarizes the ethnomethodological critique and approach as follows:

the here-and-now of observed data ought not to be allowed to stand in proxy for "unseen" phenomena or patterns independently theorized as necessities, certainly not patterns that invoke imagery with their pieces linked together and stretching off into hypothetical space. The approach calls for a more problematic relation between multiple observations than simply glossing them into categories that fit into a logically prearranged theory' (p. 797).

These questions about the prospects for an organization science could be removed with observations that verify the properties or actions attributed to organizations. However, short of this, the concept of organization has the ambiguous status of an idea; perhaps one that names an object that others could agree to, but perhaps, instead, one that names a figment of the imagination. With organizations, as with everything else, seeing is believing and it is the best place for a science to begin.

For the would-be scientist, the challenge posed by being unable to see organizations can be compared to that posed by a large jigsaw puzzle that comes without a guiding picture of the whole. Such a jigsaw puzzle would find us perpetually lost in one region or another, in a vain search for similar appearing pieces to assemble. If the puzzle happened to be a landscape (though we would have no way of knowing), we might get as far as assembling regions of blue sky, clouds, fields, trees, or perhaps flowers. But no farther. We would never know if similar pieces made up a single region or many (e.g. one cloud or many), or how to coordinate 
dissimilar regions (indeed, it might never occur to us to try. for these would seem separate puzzles, i.e. organizations unto themselves). Nor would it do any good to focus on pieces that bridge between regions, because there is no telling, without a concept of the whole, whether they are truly boundary pieces or rather mottled pieces belonging to a region of their own. In desperation. we might look to other puzzles for guiding pictures of the whole (e.g. a portrait, still-life, or city-scape). Even though such pictures would be misleading (because they belong to other puzzles), we could not know this (because we are lost anyway) and for a time at least we would be grateful for having our hopes restored. Surely this is no way to solve a puzzle, or to build a theory of organization.

\section{Organizations and Science}

Scientific theorizing is a form of intellectual life that juxtaposes seeing and saying. It is the perplexing art of explaining experience. It is perplexing because there is no simple basis for coordinating experiences and explanations, the two are linguistically incommensurable. It is an art. because the criteria for a good theory are largely aesthetic. Even though experiences do not literally have causes or reasons, scientific theory purports to say what they are. Apples do not fall to earth because of gravity; they fall to earth and we call this gravity. Socrates is not mortal because he is a man; he is mortal and we attribute this to his being a man. As we show below, the facts of experience bear a paradoxical relation to the principles that are invoked to explain them.

\section{Language Games and Science}

Experiences and explanatory principles have different uses, and therefore different meanings. Whereas experiences predicate a subject (who does the experiencing), explanatory concepts do not. The experience of a red apple implies a perceiving subject, but the concept of a gravitational force that brings the apple to earth does not. By being experienced, the red apple is substantiated in a way that the force of gravity is not. The apple can be pointed to and verified by others. This contrasts with the force of gravity which cannot be experienced directly, and for this reason cannot be made into an object. Rather, gravity must be inferred from the collateral evidence of its supposed consequences (e.g. mass attraction. a feeling of weight).

Experiences and explanatory concepts also differ in their susceptibility to reasoning. Explanatory concepts are the stuff of logical reasoning and. indeed, are the medium in which such reasoning takes place. In contrast. it is impossible to reason logically with experiences. Whereas we can deduce that Socrates is mortal from antecedent knowledge that Socrates is a man and that all men are mortal. we cannot deduce the experience 
of Socrates being mortal from the experience of Socrates being a man and all men being mortal. Aside from the fact that there are no experiences of humanness and mortality to be had, they could not function as logical elements in any case - and this because they are not the sorts of things that one can reason oneself into. One experience cannot be deduced from another.

Following Wittgenstein (1953), it is possible to view experiences and explanatory concepts as elements of distinct language games. This conception of language games reminds us that ideas have different uses and purposes and that they function in different linguistic environments (hence the metaphor of 'games'). This conception also reminds us that, because of these differences, ideas can sometimes be difficult to integrate, or even incommensurable. According to Wittgenstein, many of the problems of philosophical analysis are actually problems of the coordination of language concepts that have widely disparate backgrounds and histories.

One of the charms and fascinations of science is that it attempts to marry the language games of experience and explanation in spite of the difficulties that this sometimes produces. This is why its truths are never settled, but are always open to criticism and debate. Theory never quite explains experience, and experience never quite proves theory. This is the key to science's dynamism. When it tends to much toward theoretical system. it is criticized for abandoning experience; and when it tends too much towards experience, it is criticized for being theoretically vacuous. Like marriages of othei kinds, this marriage of language games never quite succeeds, but is somehow satisfying enough.

\section{Language Games and Organization Science}

The concept of language games suggests that an important impediment to organization science has been that its principal concept - organization - does not participate equally in the two language games of experience and explanation. As we have seen, there is no experiential or perceptive concept of organization to go along with the many and varied theoretical concepts of organization. The negative result is that there is no constructive interplay between theory and experience. no agreement about what should be theorized, and no concern for operationalization and empirical testing. We don't know what organization theory is about, much less whether it is true.

The loss of theoretical discipline that comes from not having experiences of organization to work with is perhaps most apparent in cases where theoretical concepts have been borrowed from more established sciences. A good example of this is the theory of evolution by natural selection, borrowed from biology. Within biology, the interplay of theory and perceptive experience is clear. For example, it is well-illustrated by Gould's (1977) essay on the natural history of the Irish Elk. First identified as a species by Cuvier in 1812, this animal is famous for its large size and 
particularly for its enormous antlers (which attained widths in excess of 12 feet). As Gould details, this giant deer (it was misnamed an Elk because of its size) created scientific controversy by raising doubts about the basic principle of natural selection. Anti-Darwinists fastened upon this creature as proof against the idea that evolutionary changes are adaptive, and for the contrary idea that these changes proceed in a fixed direction, whether adaptive or not. In their view, the Irish Elk perished because its antlers became too large. Alternatively, Huxley and others conceded that large antlers may not have been adaptive, but defended the principle of natural selection by linking antler size to body size, which was an adaptive advantage (the principle of allometry). Also rising in defense of natural selection was Gould himself, who argued oppositely that large antlers actually provided a selective advantage. The large antlers of the male, Gould argued, doubled as a highly visible symbol of status in sexual selection by females and as a device for self-protection from other males competing for dominance. According to Gould, the Irish Elk perished for more prosaic reasons of climatic changes.

We see in this example how the theory of natural selection interacts with experiences (based on the fossil record) to generate a reason and basis for scientific inquiry. The confrontation of the two offers a basis for testing and modifying theory (such as by introducing Huxley's hypothesis of allometry, or Gould's notions of sexual selection and protected dominance contests). It also offers leads for expanding the scope of experience (such as by looking at the ratio of body size and antler size to test allometry; by looking more closely at the fossil record to see if the antlers could have functioned as Gould proposed).

By contrast, there is no comparable interplay between the theory of natural selection and experiences in population studies of organizations. This example is from Freeman (1982: 7):

'Suppose we were studying the populations of men's liberal arts colleges and women's liberal arts colleges during the 1960 's and 1970 's. We would see that the women's colleges were dying at a much more rapid rate than the men's colleges. The question that comes immediately to mind is why do the men's schools compete successfully, whereas the women's schools do not? A difference of some importance is the fact that men's colleges are more likely to be endowed than are women's colleges. . . Obviously, it is always better to have a large endowment than a small one. And just as obviously, when times are difficult more organizations of all kinds will fail than when the funding environment is munificent. It is the combination of the two that is most interesting for its effect on the mix of colleges observed in the early 1980's.'

These appear to be similar dynamics of natural selection, but the appearance is misleading because it is based on metaphor, and not on strict analogy. As compared to the example of the Irish Elk, where the mechanism of natural selection explains the net mortality of a concretely experienced animal in terms of its specific characteristics operating in a specific environment; in this example, natural selection explains only the net mortality of characteristics which are claimed to be those of a form 
of organization in an environment, but which cannot be contested as such. Here, it is not the fate of organizations that is explained, but rather the fate of certain characteristics, such as gender of the student body and size of endowment. The organization form is not given before the fact, but is defined after the fact - in Freeman's phrase, as a 'bag of variables that covary as a result of differential net mortality' (Freeman, 1982: 9. emphasis added). The principle of natural selection does not explain organization form; instead, it defines it for us, and as a definition, this principle cannot be tested. As compared to its more advanced cousin in biology, the theory of organizational selection does not involve the same tension between theory and experience and it is not scientific in the same way.

The comparison of these two cases makes bold the point that scientific inquiry proceeds differently when guided by experience. When all eyes are focused on the phenomena, there are discussions about what is observed, about how to look at it, and about what aspects or properties are significant theoretically. Theory develops alongside observation, and relates to it as a kind of introspection, literally as 'in-sight'. Moreover, because the grounds for endorsing one theory or another are apparent, they can be discussed and debated. Theoretical advances are occasioned, not by bully arguments (although rhetoric is important). but by the feeling of satisfaction that comes from a new theory that is more sympathetic to experience. However, when there is no experience to discipline conceptualization, alternative theories are left to scrap among themselves for status. The result is a reform-school mentality of every theory for itself. Thus, within organization studies, functionalists argue that structuralists leave out purpose, and they, in turn, maintain that functionalists presume too much. Strategy theorists take both to task for belittling individual action and choice, while ecologists complain that individual agency is overstated, and that organizations are subject instead to powerful inertial forces which limit choices. This is not a proud contest of strength in fitting the facts, so much as unseemly conflict of weakness and name-calling. Whereas we might want to call this science, it is actually of a different order entirely - something more akin to religion, or better perhaps, superstition (literally, a clash of ideas that 'stand over' the facts).

\section{Beyond Language Games}

The question arises of how theories of organization could prosper in the absence of substantiating experience. Here, again, the concept of language games offers a clue. We believe that the estrangement of organization theory from experience is partly the result of taking the idea of language games too seriously - that is, of believing that because explanatory concepts and experience concepts can be seen to participate in different language games, there is no chance or point in trying to relate 
the two. Taken to its extreme, this is to believe that the two are logically incommensurable.

This idea has a long and venerable history that can be traced back at least to Plato, who maintained that theoretical facts are ideal and that they can be glimpsed only by reasoning beyond the fallible evidence of the senses. This idea was given further impetus by Descartes who divided the world into an objective, material realm (matter), and a subjective, mental realm (mind) - and in so doing saddled philosophy ever since with the burden of relating the two. Today, this idea takes many forms. It is written large in schools of rationalism that deduce new theoretical concepts from old ones, without so much as a sideways glance at experience. It is expressed in schools of psychology that conceptualize the development of the mind as a process of learning how to go beyond the information given (e.g. Bruner 1974). This idea is reflected in a kind of statistical imperialism, too often found in social science, which pronounces quantitative statistical analyses superior to 'noisy' and 'ungeneralizable' experiences of single cases. On this basis, sophisticated statistical analyses (e.g. factor analysis. LISREL) are applied without regard for the quality of the data used, or for the logical issues involved when generalizing from groups of cases to individual ones

Few ideas have created more confusion or done more harm to our understanding of ourselves and the way we know things. This idea suggests that since theoretical concepts and perceptive experiences are essentially different, picking one is somehow tantamount to taking sides against the other. Yet, Wittgenstein's essential insight about language games is precisely that they are 'games' and not settled truths. Philosophy, he wrote, is a battle against the bewitchment of our intelligence by language. Although theoretical concepts and perceptive experiences can be circumscribed within different language games, they need not be. It is also possible and desirable to see them in an alternative way as related within a common language game. Seeing them in a second way multiplies our understanding, and makes it possible to understand how science could purport to marry the two.

An alternative, which we are hardly the first to suggest, is to see theoretical concepts and perceptive experiences as developing from essentially the same act of mind, and as differing mainly in degree of abstraction (experiences being closer to sensation and theoretical facts farther away). Instead of distinct types, we can imagine a continuum that marks a single route to understanding. with perceptive experiences being nearer the departure point and theoretical concepts nearer the destination. This alternative thus reconceptualizes our usual ideas of both theory and experience. Theoretical concepts become part experiential and perceptive experiences become part theoretical, and there is no clear break or demarcation between the two, but only shadings of emphasis. A significant consequence of this view is that it makes curious our usual idea that experiences are more subjective than theoretical concepts. Rather, it suggests that the latter actually involve more of the mind in their making 
and thus have more of the subject in them. Although the thing-like appearance of theoretical concepts may suggest objectivity, when we follow these 'disembodied' ideas back to their sources, we go back upon a process of abstraction that is as subjective as can be.

This view of theory and experience led Dewey (1958: 8) to reserve a special meaning for the word 'experience' because it 'recognizes in its primary integrity no division between act and material, subject and object, but contains them both in an unanalyzed totality'. Similarly, James (1904) described experience as 'double-barrelled', noting that it encompasses the single-barrelled words of both 'thing' and 'thought'. Experience refers both to perceiver and fact perceived and conceives them not as two, but as an indivisible one. On this view, there are not theoretical facts and experiences, but only experiences which, from certain vantage points, might provisionally be called 'facts'. This concept of experience (which appears in contemporary linguistic philosophy as the concept of 'seeing as', see Wittgenstein 1953; Hanson 1969) forges a connection between experience and theory, and grounds the latter firmly in the former. Its main advantage for purposes of analysis is that it does not worry about giving undue emphasis to one or the other, or about how to put them back together - which, as Dewey drolly puts in, is something that not even all the king's men can do.

For the purposes of this paper, this alternative view of theory and experience is significant because it compels us to keep a steady eye on the phenomena in question. If it is a mistake to envisage sharp lines between theoretical concepts and experiences, then we must insist that all concepts be part theoretical and part experiential. Although lines between the two can be drawn, they come at the cost of neglecting experience as the mainspring of theoretical insight. As Barzun (1983: 63) has forcefully argued, to keep hold of concrete experience is to value theoretical concepts so much as to be fastidious in their use and demanding about their quality. Without experience to guide it, theory can stray too far from the real and become lost in the web of its own logic. Further, this alternative view reminds us that the landmark achievements of science have always been occasioned by advances in the capacity to experience - e.g. Galileo's telescope, electron microscopy, nuclear accelerators and bubble chambers, computer simulation, and mathematics. With deeper and broader experiences come new insights (literally, new 'seeing intos'), and more fruitful and felicitous theoretical abstractions. Finally, this view suggests caution when interpreting recent arguments that organization theories can be improved by insisting on more rigorous formulations, such as by mathematics (e.g. Camerer 1985). Mathematics offers powerful means of expression when its concepts can be checked against experience, but, when it is pursued as an end unto itself, mathematics also can be an evasion of experience, as sometimes happens in neo-classical economics. 


\section{Prospects For a Science of Organizations}

The discussion above can be adduced to support opposed conclusions about how organization studies should proceed - one. despairing and destructive, the other, hopeful and constructive. The first conclusion is that a scientific theory of organizations is not practicable and that the sooner this is recognized the sooner research attention can shift to more productive questions. This conclusion recalls well-known and wellspoken calls for theories grounded in experience (e.g. Glaser and Strauss 1967), and for theories of the middle-range that conform more closely to experience (e.g. Merton 1967). However, since this conclusion is depressing and leaves little more to say, we note it in passing while remaining mindful of its disquieting message.

The second and more hopeful conclusion is that more work is needed to bring organizations within the compass of experience and within the range of scientific abstraction. This admonition is perhaps more welcome because it gives hope to our theoretical ambitions. With a close enough look at organizations it may yet be possible to establish a secure scientific basis for organization theory.

\section{Expanding the Scope of Experience: New Sensitivities}

Insofar as theory thematizes an experienced world, it is served best by the most penetrating and encompassing experiences. The pressing need of organization theory is for experiences of organizations qua organizations - that is, for experiences of the whole, and not just of its presumed parts. To satisfy this need, new sensitivities are required. Ways must be found to bring organizations within the limited compass of human perception and reason. Just as cellular biology awaited the invention of the microscope, and atomic physics the accelerator, so too a true study of organizations awaits the development of instruments capable of bringing its subject within human perceptibility.

It is hardly possible to exaggerate our present ignorance, or the scale of the task we face. In view of the mammoth size, diversity, and dispersion of large organizations, the problem of domesticating them within the bounds of human sensibility is daunting. This problem is compounded by the fact that organizations can be described either in physical terms of matter and motion, or in mentil terms of information, meaning, and feeling. Whereas the physical bearing of organizations may be easy to understand (if we can get enough of a look at organizations to see it), the mental or symbolic bearing of organizations is sure to be more diffcult to comprehend. Physical fact is but one piece of the puzzle and is joined by all the nuances and ambiguities of human nature, language, culture, mythology, and history. Thus, to experience organizations in their totality requires also a high and perhaps impossible degree of anthropological awareness.

Daunting as the project may be, there are hopeful signs of progress. 
Although it remains to be seen what new sensitivities may emerge, and what kinds of instruments will bear them. there are intriguing intimations in contemporary research. One is the ongoing effort to develop comprehensive maps of organizations - for example, as networks of action and interaction, or as networks of causal reasoning and meaning (e.g. Burt 1982: Bougon. Weick and Binkhorst 1977). For example, Bougon et al. (1977) have mapped the process by which the members of an organization (the Utrecht Jazz Orchestra) established a common concept of a task and a division of labour (a reading of a new piece of music). When presented in visual form, either on paper or with computer assisted imaging. these maps enhance our visual powers by condensing large tracts of organized activity into a single surveyable region. In recent years especially, the comprehensiveness of such network studies has been greatly expanded by the availability of high-speed computation. Although there remain questions about whether an organization can be glimpsed from studies of relational networks (e.g. would this constitute a new. computer-assisted form of reification?) and about the sensitivity and resolving power of current techniques (e.g. of measurement, aggregation procedures), this line of research offers a reason for hope.

Another intimation of things to come is the more recent effort to reproduce aspects and phenomena of organization by means of computer simulation (e.g. Axelrod 1984; Masuch and LaPotin 1989). These studies take a different approach to understanding complex organizations. Instead of trying to map the elements of organizations, they propose to learn about organizations by reproducing their capacities and tendencies. For example, Axelrod (1984) has developed computer simulations (based on the iterated Prisoner's Dilemma game) which show how one important quality of organization, the norm of cooperation, can emerge among independently motivated and self-interested actors. Although these studies do not look to experience as the immediate basis for theoretical abstraction, they do call upon it after the fact when comparing theory against known characteristics of organizations. This resembles the approach taken by cognitive scientists who investigate the human mind by creating artificial forms of intelligence. Whether this approach will prove any less controversial as a mode of inquiry into organizations (as studies of artificial intelligence are of human intelligence) remains to be seen.

If we add to these methods others that might prove illuminating (e.g. comprehensive ethnographies, or perhaps organization stimulations, or even experiments), or if we learn how to combine methods - for example, simulation with network analysis - the possibilities of productive insight may be multiplied. Although their promise remains to be seen, some of today's methods could conceivably do for the field of organization studies what the microscope and accelerator did for theirs. 


\section{Expanding the Scope of Experience: Wider Sensitivities}

The salvation promised by new instruments should not, however. distract or deter us from developing our native ability to experience organizations. Perhaps there are hidden or unobvious realms of intuition or feeling by which we can know organizations, without special prostheses.

It is perhaps not too farfetched to suggest that even though organizations cannot be seen, they can be felt. Perhaps there are experiences of organization at the level of feeling that can be grasped by taking a different kind of 'look' at them. Maybe there is an experientiable concept of organization akin to the cozy 'we' feeling that is sometimes noted of small groups (see Sandelands and St. Clair 1992) or to the feeling of 'communitas' that has been identified with tribal or religious gatherings (Turner 1974). To know organizations in this way would require the perceptive sensitivity of the novelist or poet. It would require an intellectual openness that is not bound to prior conceptions, and an emotional openness that finds room for experiences that are probably more diffuse, intuitive, and perhaps more visceral than those that appear to the senses.

Indeed, it is an affecting lesson of the humanities that its intellectual giants are profound observers of social life. Their genius is their ability to see things in surprising ways - ways which are recognizable, yet recognizably different from our own. An obvious difference is that the poet or novelist typically looks at things with different purposes in mind and from a different point of view. More so than the ordinary person. they are attuned to feeling qualities that escape ordinary attention or awareness, and more so than the average reader of this journal, they are not as enamoured or prejudiced by prior conceptions of organization.

Within organization studies, this sort of perspective is probably more available to newcomers to the field who, because they are unschooled. may be able to 'see' (feel) aspects of organizations that are hidden from more experienced eyes. They may have more of the innocence sought out by phenomenologists in their method of wessenchau, which begins with pure experience. and then builds concepts by looking for invariants amidst the ongoing flux. For established organization theorists. for whom innocence is long lost, a fresh perspective can perhaps be emulated by switching among alternative preconceptions. This at least is the reasoning sometimes given by theorists who advocate taking multiple perspectives in the study of organizations (e.g. Morgan 1986).

By making common cause with poets, novelists, or novices, we do not mean to suggest that these people can see things that the established organization scientist cannot. We mean only to urge a methodological point; namely, that the way we see can determine what we see. We would in no way deny the scientist's charge that the reports of novices or litterateurs are loose, subjective, unrigorous, and often unreplicable. In the best examples of both, there is nothing obvious or even consistent 
in what the author is trying to say. However, this must be weighed against the litterateur's charge that science is dry, intellectual to a fault, and guilty of fragmenting the whole beyond recognition and feeling. As the poet Ezra Pound once commented, the superiority of poetry lies in the fact that it can evoke a mental-emotional complex of imagery and feeling in an instant of time, and that is one thing analytical methods just can't deliver. The glory of the novel, according to one of its contemporary masters, Milan Kundera, is that it is equipped 'to express and convey a certain kind of essential truth that the methods of analytic rationalism are forced to ignore'. This essential truth is the 'wisdom of uncertainty' and the 'inescapable relativity and ambiguity of human affairs'. Because the novel's essence is not clarity and simplicity, but ambiguity and complexity, every novel says to the reader: 'Things are not as simple as you think. 'It is just here that we come upon the novel's eternal truth. Moreover, as against a scientific modernity that has 'propelled man into the tunnels of specialized knowledge', the novel at its best enables us to see ourselves and the world as a whole.

It is somewhat along these lines that conflict arises within organization studies about the legitimacy and need for methods like those used in the humanities (e.g. clinical observation, case study, ethnography, impressionist tales) (Zald 1993). Sometimes this conflict is rehearsed in debates about the virtues of qualitative versus quantitative research methods. However, too often these debates descend to pleas by proponents of the former for a begrudged acceptance by proponents of the latter. We believe the debate is mistaken. When we focus squarely on perceptive experience as the basis for theoretical abstraction, we see, along with Glassie (quoted in Harper 1987), that there is no opposition among methods, between science and art, organization studies and the humanities. Rather, we are united in:

but one enterprise. We could call it historical ethnography or local history or folklore in context or the sociology of the creative act or the ecology of consciousness - the potential for flashy neologism seems boundless - but whatever its name, study is distorted and reality is mangled when disciplines harden into ideology. categories freeze into facts, and the sweet, terrible wholeness of life is dismembered for burial.

... if work is good, old categories will slip and shift, and then melt away as we find the place where social science joins the humanities, where art and culture and history, time and space, connect, where theoretical and empirical studies fuse.'

To be sure, these ideas for enhancing the experientiability of organizations are preliminary, ad hoc, and hardly suggest the force of a breakthrough. We suspect that if a way to experience organizations comes, it will come as a revolution in methods, and not as an incremental improvement over existing techniques. The main reason for including suggestions is to sustain the hope that a way out of the problem of experience can be found. For the alternative to hope is despair. 


\section{Conclusion}

'In the modern world, the celibacy of the medieval learned class has been replaced by a celibacy of the intellect which is divorced from the concrete contemplation of the complete facts.' (Whitehead 1925)

Whitehead spoke thus of the danger to science of losing touch with concrete experience. A science is fully alive and creative when wide-cyed and involved; when it sees, touches, hears, tastes, and feels. Intellectual celibacy, cut off from sensuous involvement, is a shame not a virtue.

To make the study of organizations more like a natural science means, above all, grounding concepts and theory in communicable and verifiable experiences. This, as Homans (1950) points out, is an exacting discipline. One must:

'. . habitually catch himself as he mouths one of the big abstractions and ask: What does this mouthful mean in terms of actual human behavior that someone has seen and reported?. . The question is devastating and we do not ask it often enough. . . . The great point is to climb down from the big words of social science, at least as far as common sense observation. Then, if we wish, we can start climbing up again, but this time with a ladder we can depend on. ( $p$. 10)

If the study of organizations is ever to be a natural science. organization researchers would do well to have the same respect for Nature that the physical and life scientists have. For these natural scientists, it is as much an axiomatic belief that nature is cleverer. subtler and more intricate than the human intellect can possibly comprehend, as it is that nature obeys certain. intellectually discerned rules or laws. Nature converses civilly with reason and logic, but yields her secrets only to perceptive experience. Inquiry must begin with the latter.

Science is justifiably admired for speaking clearly and precisely. It is admired even more for questioning everything not vouchsafed by experience. As Durkheim put it. "science is conscience raised to its highest degree:. Such is the conscience called for by Lewin (1947) when he insisted that concepts of social science be founded upon concrete experience, or not at all. Such is the conscience needed today by organization theory if it is to become scientific in this sense.

Note

*We are grateful to Tom D'Aunno. Jane Dutton. Sunder Narayan. Rick Price. Anat Rafaeli, Karl Weick, and the editor and reviewers of this journal. for their constructive suggestions on earlier drafts of this manuscript. 


\section{References}

Allport. Floyd H.

1962 'A structuronomic conception of behavior: Individual and collective'. Journal of Abnormal and Social Psychology 64: 3-30.

Axelrod. Robert

1984 The evolution of cooperation. New York: Basic Books.

Barnard, Chester I.

1938 The functions of the executive. Cambridge. MA: Harvard University Press.

Barnett, William P., and Glen R. Carroll 1987 'Compctition and mutualism among carly tclephonc companies". Administrative Science Quarterly 32: 400421 .

Barzun, Jacques

1983 A stroll with William James. New York: Harper and Row.

Blau, Peter

1964 Exchange and power in social life. New York: Wiley.

Blau, Peter, and Richard Scott

1962 Formal organizations: A comparative approach. San Francisco: Chandler

Bougon. Michel, Karl Weick, and D. Binkhorst

1977 Cognition in organizations: An analysis of the Utrecht Jazz Orchestra'. Administrative Science Quarlerly 22: 606-639.

Bruner, Jerome

1974 Beyond the information given. New York: Anchor.

Burt, Ronald S.

1982 Toward a structural theory of action: Network models of social structure, perception, and action. New York: Academic Press.

Camerer, Colin

1985 'Redirecting research in business policy and stratcgy'. Strategic Management Journal 6: 1-15.

Child, John

1982 'Organization structure, environment and performance - the role of strategic choice'. Sociology 6: 122.
Dewey, John

1958 Experience and nature. New York: Dover.

Drazin. Robert and Lloyd E. Sandelands

1992 'Autogenesis: A perspective on the process of organizing'. Organizational Science 3/2:230-249.

Durkhcim, Emile

1933 The division of labor in society. Trans. by G. Simpson. New York: Free Press.

Eisenberg, Eric M.

1990 Jamming: Transcendence through organizing'. Communication Research 17: $139-164$.

Fiol, C. Marlene

1989 'A semiotic analysis of corporate language: Organizational boundaries and joint venturing'. Administrative Science Quarterly 34: $277-$ 303.

Frecman, John

1982 'Organizational life cycles and natural selection processes' in Research in Organizational Behavior, Vol. 4. B. M. Staw and L. L. Cummings (eds.), 132. Greenwich, CT: JAI Press.

Garfinkel, Harold

1967 Studies in ethnomethodology. Englewood Cliffs, NJ: PrenticeHall.

Giddens, Anthony

1979 Central problems in social theory. Berkeley, CA: University of California.

Glaser, Barney, and Ansclm Strauss

1967 The discovery of grounded theory. Chicago: Aldine.

Gould. Stephen J.

1977 Ever since Darnin. New York: Norton.

Hambrick, Donald C., and Phyllis Mason

1983 'Upper echelons: The organization as a reflection of its top managers'. Academy of Management Review 2: 193-206.

Hannan, Michael, and John Freeman

1977 'The population ecology of organizations'. American Journal of Sociology 82: 929-964. 
Hanson, Norwood R.

1969 Perception and discovery. San Francisco: Freeman

Harper, Douglas

1987 Working knowledge. Chicago: University of Chicago.

Hilbert. Richard A.

1990 'Ethnomethodology and the micromacro order'. American Sociological Review 55: 794-808.

Homans, George C.

1950 The human group. New York: Harcourt and Brace.

Homans, Gcorge C.

1967 The nature of social science. New York: Harcourt and Brace.

James, William

1904 'Does consciousness exist?' Journal of Philosophy 1: 477-491.

James, William

1911 Some problems of philosophy. New York: Longmans.

Katz, Daniel, and Robert Kahn

1978 The social psychology of organization, 2nd edition. New York: Wiley.

Lawrence, Paul, and Jay Lorsch

1967 Organization and environment. Cambridge. MA: Harvard University Press.

Lewin. Kurt

1947 Field theory in social science. D. Cartwright (ed.). New York: Harper.

March. James G.. and Herber A. Simon 1958 Organizations. New York: Wiley.

Masuch, Michael, and Perry L. LaPotin

1989 'Beyond garbage cans: An Al model of organizational choice'. Administrative Science Quarterly 34: 38-67.

Merton, Robert K.

1967 On theoretical sociology. New York: Free Press.

Mohr, Lawrence

1982 Explaining organizational behavior. San Francisco: Jossey Bass.
Morgan. Gareth

1986 Images of organization. New York: Sage.

Rylc, Gilbert

1949 The concept of mind. Chicago: University of Chicago Press.

Russell, Bertrand

1921 The analysis of mind. London: Unwin.

Sandelands. Lloyd E.. and Robert Drazin

1989 'On the language of organization theory'. Organization Studies 10/4: $457-477$.

Sandelands. Lloyd E. . and Lynda St. Clair 1993 'Toward an empirical concept of the group". Unpublished working paper. University of Michigan. Ann Arbor.

Scott, W. Richard

1981 Organizations: rational, natural, and open systems. Englewood Cliffs. NJ: Prentice-Hall.

Sclznick, Philip

1957 Leadership in administration. New York: Harper and Row.

Simon, Herbert A.

1976 Administrative Behavior. 3rd cdition. New York: Free Press.

Thompson, James D.

1967 Organizations in action. New York: McGraw-Hill

Turner. Victor

1974 Liminal to liminoid in play, flow and ritual: An essay in comparative symbology. Rice University Studies 60: 53-92.

Van Maanen, John, and Stephen Barley

1985 Cultural organization: Fragments of a theory in Organizational Cul. iure. P. J. Frost et al. (cds.). 31-54. Beverley Hills, CA: Sage.

Weick, Karl E

1979 The social psychology of organizing. 2nd edition. Reading, MA: Addison-Wesley.

Wheclwright. $\mathrm{P}$.

1962 Metaphor and reality. Bloomington. IN: Indiana University. 
Whitehead. Alfred N.

1925 Science and the modern world. New York: Macmillan.

Whitchead. Alfred N.

1933 Adventures of ideas. New York: Free Press.
Wittgenstein, Ludwig

1953 Philosophical investigations. New York: Macmillan.

Zald, Maycr

1993 'Organizational studies as a scientific and humanistic enterprise: Towards a reconceptualization of the foundations of the field'. Organization Science, in press. 